\title{
WAYANG DAN BATIK SEBAGAI WAHANA PRAKTEK DIPLOMASI KEBUDAYAAN
}

\author{
Andrik Purwasito ${ }^{1}$, dan Erwin Kartinawati ${ }^{2}$ \\ ${ }^{1}$ Prodi Hubungan Internasional Universitas Sebelas Maret, email : andrikpurwasito@ staff.uns.ac.id \\ ${ }^{2}$ Prodi Ilmu Komunikasi Universitas Sahid Surakarta, email :erwinpurwasito@ gmail.com
}

\begin{abstract}
Abstrak
Diplomasi budaya adalah bentuk diplomasi yang mengangkat materi seni-budaya, baik berupa seni pertunjukan, seni tari, seni pedalangan, seni suara atau seni bela diri, termasuk kuliner, sebagai bahan atau materi untuk diplomasi. Diplomasi budaya, merupakan bentuk halus dari hubungan antar negara, dan memiliki peran penting dalam ikut menyumbangkan perannya bagi perdamaian dunia. Oleh sebab itu, diplomasi budaya digunakan sebagai upaya untuk mencapai tujuan nasional melalui cara-cara yang lebih lunak. Oleh karena itu, diplomasi budaya juga disebut sebagai soft power diplomacy. Tulisan ini untuk menjelaskan salah satu praktik soft power diplomacy yang dilakukan oleh aktor non-negara, yaitu pengalaman individu penulis sendiri, utamanya menggunakan wayang kulit, kuliner dan batik. Penggunaan ketiga produk budaya Indonesia ini didasarkan pada hasil penelitian yang penulis lakukan mengenai pentingnya diplomasi berbasis kearifan lokal, antara lain berjudul "Diplomasi Multi-jalur Berbasis Genius Lokal. ". Isinya antara lain adalah wayang kulit dan jenis seni-budaya lainnya, seperti kuliner dan seni sastra, dapat diangkat sebagai metode pembelajaran dalam domain hubungan internasional. Selain sebagai alat diplomasi, penggunaan wayang, kuliner dan batik juga diimplementasikan sebagai wahana praktik diplomasi kebudayaan, sekaligus sebagai upaya pelestarian seni dan budaya khas bangsa Indonesia.
\end{abstract}

Kata kunci : seni, batik, budaya, diplomasi, wayang kulit, soft power.

\section{WAYANG AND BATIK AS A MEDIA FOR CULTURAL DIPLOMACY PRACTICE}

\author{
Andrik Purwasito $^{1}$, and Erwin Kartinawati ${ }^{2}$ \\ ${ }^{1}$ Prodi Hubungan Internasional Universitas Sebelas Maret, email : andrikpurwasito@ staff.uns.ac.id \\ ${ }^{2}$ Prodi Ilmu Komunikasi Universitas Sahid Surakarta, email :erwinpurwasito@gmail.com
}

\begin{abstract}
Cultural diplomacy is a form of diplomacy that promotes art and culture materials, whether in the form of performance art, dance, puppetry, sound art or martial arts, including culinary, as material or material for diplomacy. Cultural diplomacy, is a subtle form of relations between countries, and has an important role in contributing its role to world peace. Therefore, cultural diplomacy is used as an effort to achieve national goals through softer ways. Therefore, cultural diplomacy is also referred to as soft power diplomacy. This paper explains one of practice of the soft power diplomacy that carried out by non-state actor, based on writer's experience, primarily using shadow puppets, culinary and batik. The use of these three Indonesian cultural products is based on the result of research that the author conducted regarding the importance of local wisdom-based diplomacy, among others entitled "Multi-track Diplomacy Based on Local Genius." Its contents, among others, are wayang kulit and other types of arts and culture, such as culinary and literary arts, can be appointed as a method of learning in the domain of international relations. Aside from being a diplomacy tool, the use of puppets, culinary and batik are also implemented as tools for cultural diplomacy practices, as well as an effort to preserve the arts and culture typical of the Indonesian nation.
\end{abstract}

Keywords: art, batik, culture, Diplomacy, puppet, soft power. 


\section{PENDAHULUAN}

Diplomasi budaya adalah salah satu bentuk diplomasi khusus menggunakan materi seni-budaya, seperti seni tari, seni lukis, seni pertunjukkan, kuliner, fesyen, seni pedalangan, serta hal-hal yang berkaitan dengan produk seni dan budaya masyarakat. Aktor dalam diplomasi biasanya dilakukan oleh negara namun dalam paper ini akan membicarakan diplomasi budaya yang dilakukan oleh aktor non-negara. Aktor nonnegara adalah siapa saja yang telah melakukan aktivitas budaya di luar negeri, tanpa memandang derajad sosial, ekonomi maupun latar belakang pendidikan. Menurut catatan sejarah, diplomasi budaya pada awalnya dilakukan oleh state (negara), terutama oleh Presiden Soekarno, yakni pertunjukan seni tari dan wayang kulit serta seni Bali. Di satu pihak, dengan berkembangnya waktu, kini diplomasi budaya dapat dilakukan oleh setiap warga negara, baik dilakukan secara langsung, yakni kegiatan budaya di luar negeri, baik secara pribadi maupun atas nama organisasi, atau diplomasi budaya melalui dunia maya (cyber-diplomacy). Aktor-aktor non-state actors tersebut lambat laun memainkan peranan penting dan signifikan dalam mempromosikan Indonesia di kancah internasional.

Di pihak lain, diplomasi budaya juga dilakukan oleh pejabat negara atau organisasi resmi pemerintah (actor negara/state actors). Pemerintah melakukan diplomasi budaya sebagai kegiatan rutin, sebagai diplomasi publik dan cara berkomunikasi secara budaya dengan warga negara asing. Dengan kata lain, diplomasi merupakan proses komunikasi budaya yang bersifat horizontal yang dilakukan oleh aktor non-negara maupun negara, yang, masing-masing bertindak sebagai komunikator, diplomat atau agen-agen promosi dalam hubungan internasional.

Diplomat adalah pelaku diplomasi budaya, khususnya bagi aktor negara. Sedangkan aktor non-negara dapat juga disebut "diplomat" dalam kapasitasnya ikut dalam kegiatan menjalin hubungan damai dan bersifat saling menguntungkan dengan negara lain. Sebagai "diplomat", aktor non-negara tidak melakukan kegiatan yang bersifat politik, sehingga dipandang dari pola komunikasi yang dilakukan, diplomasi budaya tidak bersifat transaksional yang biasanya menghasilkan bentuk diplomasi menang atau kalah. Diplomasi budaya merupakan ajang promosi dibandingkan dengan target-target politis. Selain berbeda dengan diplomasi politik, diplomasi budaya juga bukan diplomasi ekonomi, akan tetapi dalam beberapa hal, diplomasi budaya juga 
menghasilkan target yang bersifat ekonomis, perspektifnya adalah keuntungan dan kerugian. Contohnya adalah diplomasi dengan menggunakan kuliner, film laga dan film animasi.

Berkaitan dengan peran yang halus, lunak dan saling menguntungkan, diplomasi budaya sering disebut sebagai soft power diplomacy (Junior, 2009). Karena pada dasarnya, diplomasi budaya memiliki tujuan untuk mencapai kepentingan nasional dengan car-cara damai. Maka sering disebut sebagai diplomasi yang bersifat tidak berterus terang, tidak semata-mata melakukan kegiatan diplomasi, dan tanpa kekerasan. Diplomasi budaya dilakukan secara halus, lunak, perlahan atau soft dan menimbulkan kekacauan. Oleh sebab itu, disebut soft power diplomacy bukan berarti bersifat tanpa kekuatan (power) dan rapuh (lemah), tetapi kekuatan yang dimiliki bersifat manusiawi, yaitu bersifat humanis dan bersahabat. Dengan kata lain, diplomasi budaya adalah kegiatan soft power yakni penggunaan kekuatan secara damai. Dengan begitu, seseorang yang melakukan kegiatan diplomasi budaya berarti kegiatan yang diarahkan untuk menciptakan persaudaraan, persahabatan, kerukunan dan perdamaian tanpa memandang warna kulit, ras, suku, agama, golongan, tingkat sosial ekonomi, melalui pertemuan yang bersahabat, win-win solution, to take and to give, sebuah arena pertukaran gagasan (share of ideas), share of experience, share of values,) sehingga pertemuan bangsa dan budaya tersebut merupakan kisah-kisah keindahan. Tulisan dalam artikel ini akan banyak berbicara tentang praktik budaya personal (nano power diplomacy), sekalipun diplomasi budaya tersebut masih memiliki bentuk lain yakni nilai-nilai politik dan kebijakan luar negeri (Junior, 2009).

Diplomasi budaya, karena sifatnya kurang bersifat politis, juga bukan berarti propaganda, yang biasanya lebih menekankan pada instrumen politik. Diplomasi budaya adalah sebuah kegiatan yang mempromosikan aspek-aspek kemanusiaan, kepribadian (mentalitas), identitas kultural melalui peragaan seni, seperti seni tari, seni suara, seni pertunjukan, seni bela diri, gastronomi, seni tradisi dan peninggalan historis, kuliner, seni kerajinan, seni peragaan busana, seni perang, seni olah-raga dan lain-lain.

Dari uraian di atas, pada dasarnya diplomasi budaya adalah dialog lintas budaya, yang tujuan utamanya adalah win-win solution, dengan cara memromosikan kehidupan damai dan pengakuan terhadap perbedaan primordial. Tugas utama diplomasi budaya adalah memromosikan peacefull coexistance, yaitu ikut serta menjaga kerukunan dan 
kebersamaan dalam hubungan internasional, selain juga ikut serta mengembangkan dan melestarikan tradisi dan warisan adiluhung dunia. Diplomasi budaya merupakan sarana saling pengertian antar bangsa, arena atau ajang dialog lintas-budaya, dengan prinsip memromosikan kehidupan yang saling menghargai dan menghormati perbedaan, nilainilai kemanusiaan, keadilan, kemakmuran dan kesederajatan.

Di bawah ini, penulis akan mengetengahkan penggunaan seni-budaya dalam praktik diplomasi di kancah dunia, berdasar pengalaman yang penulis lakukan di beberapa negara baik Eropa (Bulgaria, Romania, Moldova), Rusia, maupun Asia (India, Jepang). Serial diplomasi budaya tersebut merupakan kegiatan visiting lectures, yang penulis lakukan sejak tahun 2015. Dalam hal itu, penulis berusaha memromosikan dan mengenalkan seni-budaya, terutama, kuliner, wayang kulit dan batik.

\section{SOFT POWER DIPLOMACY}

Titik keberhasilan soft power diplomacy adalah saat kegiatan kita mendapat pengakuan dari negara lain (Junior, 2009). Dalam praktik diplomasi budaya, hal-hal yang perlu dipertimbangkan adalah materi seni budaya dan sasaran atau publik dan komunitas yang dituju. Publik adalah ruang sosial-budaya dimana program akan dijalankan. Hal lain dari diplomasi publik, berkenaan dengan materi atau program yang ingin dijual (ditawarkan). Terakhir, hal yang berkaitan dengan packaging (kemasan program), yakni bagaimana kemasan program yang akan disampaikan kepada publik. Packaging ini meliputi penggunaan bahasa, bahasa internasional atau bahasa lokal, dan juga materi termasuk penggunaan idiom-idiom lokal. Guna menjalankan itu semua, semua berpulang pada aspek dan azas kemanusiaan, seperti etika, moralitas dan sopansantun budaya setempat yang harus dipelajari secara baik (Purwasito, 2015), agar tidak terjadi kesalahpahaman dan konflik.

Diplomasi budaya adalah soft power, sehingga secara konseptual merupakan kebalikan dari hard power. Pencapaian kepentingan nasional dalam diplomasi budaya akhirnya juga bersifat lunak (soft interest). Artinya, menjalankan diplomasi budaya adalah "nglurug tanpa bala", yakni berdiplomasi tanpa melibatkan angkatan bersenjata, nuklir dan teknologi militer. Nglurug tanpa bala merupakan konsep dalam peribahasa Jawa yang menekankan pada upaya bagaimana mampu "mengalahkan" lawan tanpa proses sadar atau proses-proses tekanan lainnya (Sosrokartono, 1988). Diplomasi 
budaya berseberangan dengan itu semua. Diplomasi budaya menjauhkan diri atau tidak melibatkan diri secara langsung dengan perang, persenjataan, konflik dan perselisihan, terorisme dan kejahatan trans-nasional. Diplomasi budaya merupakan pertukaran serta transaksi gagasan, dan bukan dalam arti perundingan. Efek dari diplomasi budaya berupa kepentingan nasional yang dicapai bersifat lunak. Meski demikian diplomasi budaya bukan berarti tanpa memperhitungkan hasil yang berorientasi pada kepentingan nasional keras, hanya saja pencapaian kepentingan nasional melalui diplomasi budaya yang dimaksud bersifat intagible (soft) interest (kepentingan yang bersifat tidak kebendaan, diplomasi yang tidak memperhitungkan untung-rugi atau kalah-menang). Pencapaian hasil diplomasi budaya yang bersifat lunak tersebut akan mampu membangun atmosfer yang kondusif bagi diplomasi yang keras/hard power diplomacy (Purwasito, 2011). Dari hal ini kami menegaskan jika kedudukan diplomasi budaya sama pentingnya dengan diplomasi ekonomi, politik dan juga militer.

Aktor diplomasi budaya, sebagaimana disebutkan di atas, merupakan representasi negara. Oleh sebab itu, aktor non-negara harus lebih berhati-hati, dan lebih sopan dalam menyampaikan pendapat dan pernyataan kepada publik asing, oleh karena ucapan dan tindakan aktor non-negara sekalipun, efeknya akan memengaruhi terhadap negara Indonesia. Pada umumnya, diplomasi budaya tersebut tidak melakukan negosiasi dalam arti perundingan yang sesungguhnya, tetapi bersifat soft negociating, yaitu menyampaikan informasi diplomasi melalui budaya tanpa memperhitungkan menang dan kalah, untung dan rugi. Dalam hal-hal khusus, diplomasi budaya yang bersifat ekonomis, seperti kuliner dan film/film animasi membutuhkan perundingan misalnya untuk perizinan dan legal standing lainnya. Oleh sebab itu, perlu diingat bahwa diplomasi budaya juga melakukan fungsi protecting yang bersifat soft protecting, yakni memberikan opini publik dan image positives dari negara kita saat berhadapan dengan negara lain. Perlindungan secara lunak berarti memberikan suasana atau atmosfer kondusif seperti memromosikan kepribadian, kebaikan dan kemurahan dan keramahan serta kejujuran dari rakyat Indonesia.

Fungsi diplomasi budaya, sebagaimana ditulis dalam Konvensi Wina (1961), pasal 3 menyatakan bahwa diplomasi yang dilakukan oleh para diplomat menyangkut tugas-tugas pokok, yaitu representing (mewakili), negociating (berunding), protecting (melindungi), promoting (memperkenalkan) dan reporting (melaporkan) (Emilia, 2013). 
Dari tugas kediplomasian tersebut aspek promoting merupakan aspek utama, sebagai ujung tombak dan basis diplomasi budaya. Memang pada dasarnya diplomasi budaya adalah suatu rangkaian kegiatan seni budaya kepada publik asing untuk mempromosikan apa saja dari negara kita, dengan tujuan utama yaitu memberikan efek baik, mendorong rasa simpati dan citra positif serta menggugah bangsa lain untuk menghargai dan menghormati bangsa dan negara Indonesia. Dengan demikian, efek diplomasi budaya juga merupakan upaya untuk membantu mengurangi ancaman dan gangguan asing, sehingga diplomasi budaya mempunyai dimensi keamanan nasional (national security). Dengan kata lain, bahwa diplomasi budaya adalah sebuah upaya untuk mengamankan secara halus ancaman, gangguan terhadap keamanan nasional dengan cara memromosikan kebaikan, keluhuran dan kebajikan Indonesia kepada kepada bangsa-bangsa lain.

Fungsi lain dari diplomasi budaya adalah bentuk laporan (reporting). Hal ini sangat dibutuhkan agar apa yang telah dilakukan dalam diplomasi budaya dapat diarsipkan, nantinya sebagai rujukan, sekaligus data laporan tersebut dapat digunakan bagi mereka yang akan melakukan kegiatan diplomasi budaya, sehingga banyak orang dapat mempelajari pengalaman tersebut dengan baik dan sistematis (Nasution, 2012). Laporan diplomasi budaya tersebut adalah bentuk pertanggung-jawaban moral dan mungkin finansial bagi yang memberikan dana (contohnya adalah diplomasi budaya yang kami lakukan di Eropa Timur, penulis memperoleh support dari Kemendikbud tahun 2015), juga di tahun 2017. Bentuk laporan publik dapat berupa laporan fisik tertulis maupun hasil olah audio-visual dan foto-foto pelaksanaan kegiatan atau rekaman video yang disebarkan melalui media sosial, seperti facebook, instagram dan youtube atau melalui saluran televisi nasional, lokal dan media massa lainnya.

Diplomasi budaya adalah soft power diplomacy, yang juga dikenal dengan diplomasi publik, berbeda dengan makna diplomasi dalam hard power diplomacy, yakni kegiatan diplomasi yang didasarkan atas konsep keamanan komprehensif meliputi keamanan dalam bidang militer, politik, dan ekonomi. Dengan demikian, diplomasi budaya lebih ditujukan untuk membangun dan membentuk citra dan dukungan publik dunia kepada Indonesia. Caranya, adalah membangun simpati dengan cara halus dan memikat warga negara atau pemerintah asing agar negara dan bangsa Indonesia semakin dikenal dunia. Korea melakukan diplomasi budaya dengan materi film dan K- 
Pop, Jepang dengan film animasi, China dan Thailand dengan kuliner, AS dengan kuliner dan film Holywood. Dengan demikian, hubungan kekuasaan dilunakkan dengan cara-cara halus melalui serangkaian aktivitas dan kegiatan budaya. Dengan kata lain, bahwa diplomasi budaya juga digunakan untuk melahirkan kesadaran kolektif guna memecahkan persoalan yang tumbuh dan meningkatkan kualitas aksi dari implementasi politik luar negeri suatu negara (Emilia, 2013).

\section{RISIKO BUDAYA}

Diplomasi sebagai sarana untuk melakukan hubungan baik dengan berbagai negara (the conduct of the relations of one state to another), bertujuan untuk memenuhi kepentingan nasional dan ikut serta dalam mengembangkan program perdamaian dunia. Diplomasi budaya sebagai salah satu sarana tersebut, memainkan peranan penting dan strategis. Selain diimlementasikan dengan cara-cara damai dan halus, diplomasi budaya telah menunjukkan peranan pentingnya dalam upaya menjembatani perbedaan dan gapgap antar bangsa yang mampu menyebabkan kesalahpahaman, prasangka dan akhirnya menanamkan benih-benih konflik dan permuusuhan antar bangsa.

Perbedaan nilai dan norma dari berbagai bangsa dalam diplomasi budaya harus menjadi pertimbangan utama, karena hal itu berhubungan dengan cara berpikir, sikap dan perilaku suatu bangsa. Terutama dalam menentukan proses pengambilan keputusan. Hal ini berkaitan erat dengan risiko politik dan ekonomi yang biasanya sulit untuk dipecahkan. Diplomasi budaya agaknya lebih dingin dan lunak untuk membantu dan mengiringi risiko budaya yang berakibat fatal. Di sini inilah salah satu unsur vital dalam diplomasi budaya, karena kemampuan memromosikan keamanan nasional secara kultural yang memainkan perannya secara halus, afektif dan damai.

Risiko budaya adalah hambatan-hambatan yang terjadi yang disebabkan oleh jurang perbedaan budaya, yang biasanya sangat sensitif. Hambatan budaya biasanya lebih disebabkan karena pola-pola berpikir dalam bentuk etnosentrisme dan stereotype, yang pada gilirannya akan berpengaruh pada reaksi, rangsangan dan respons individu dalam suatu tindakan (Purwasito, 2015). Untuk mengatasi hambatan tersebut, diplomasi budaya harus diarahkan untuk menjamin tercapainya rasa penghormatan dan penghargaan terhadap perbedaan. Dalam hal ini, diplomasi budaya diarahkan untuk 
menciptakan atmosfer yang kondusif, pencitraan positif, diukur dengan opini publik yang menghormati budaya kita.

\section{WAYANG DIPLOMASI}

Seperti yang telah kami kemukakan di bagian abstrak, tulisan ini mengangkat bagaimana praktik diplomasi budaya dijalankan di beberapa negara sesuai yang penulis lakukan. Program diplomasi budaya pada program studi (Prodi) Hubungan Internasional, FISIP Universitas Sebelas Maret (didirikan 2012), memunyai dua kompetensi yakni kompetensi dalam bidang : (1) diplomasi, (2) kerjasama internasional. Untuk memperkuat kompetensi tersebut, Prodi mulai memilih unggulan prodi yaitu dengan ungkapan soft power diplomacy. Unggulan tersebut bukan berarti mengabaikan hard power diplomacy, keduanya tetap diajarkan secara seimbang dan merata. Unggulan dipilih berbasis visi misi universitas, fakultas dan program studi. Dengan demikian, unggulan Prodi akan memperkokoh visi dan pencapaian misi fakultas dan universitas. Dari situ, Prodi perlu membangun rencana yang terstruktur sampai tahun 2030. Guna mendukung tercapainya unggulan tersebut, Prodi menentukan beberapa mata kuliah yang berhubungan erat dengan bidang diplomasi budaya, yaitu mata kuliah Teori Diplomasi, Praktek Diplomasi, Negosiasi dan Lobby, Komunikasi Internasional dan Diplomasi Publik.

Tahun 2013, Prodi mencanangkan wayang edutainment, yaitu mengajar menggunakan media wayang kulit. Wayang edutainment telah diselenggarakan selama empat kali dengan pementasan kurang lebih empat hingga delapan jam, pagi hari atau malam hari. Pementasan sangat bergantung pada kondisi ruang dan waktu. Untuk melihat bagaimana pembelajaran tersebut diadakan, pembaca dapat melihat di http://youtube.com dengan mengetik wayang edutainment.hi.uns.

Wayang edutainment telah mendorong Prodi meningkatkan media wayang sebagai wahana wayang diplomasi. Selama tahun 2014, kami telah melakukan uji coba dan engineering message yaitu fokus pada cara menjadikan wayang sebagai media diplomasi. Maka, disusunlah wayang diplomasi berbasis empat pilar utama, yang membedakan dengan pementasan wayang pada umumnya. Empat pilar tersebut adalah : (1) Durasi, (2) Properti (3) Bahasa, (4). Pengiring.

Durasi (1) yang dibutuhkan untuk wayang diplomasi tergantung pada kebutuhan, dari 30 menit sampai 2 jam. Waktu yang dipilih dapat berlangsung pada malam hari, 
siang hari, sore hari, pagi hari, tergantung dari tempat dan waktu yang tersedia. Artinya, waktu yang dibutuhkan sangat fleksibel. Properti (2) wayang menggunakan piranti simpel dengan menggunakan layar MMT sehingga simpingan wayang bukanlah wayang asli, tetapi menggunakan foto. Simpingan adalah barisan wayang yang dijajar di kanan kiri dalang saat pertunjungan wayang kulit. Batang pohon pisang (gedebog) yang biasa digunakan untuk menancapkan wayang, diganti dengan gabus untuk tanaman hias. Peralatan lain seperti keprak dan kotak kayu, digunakan seadanya. Dari alat seadanya itu, yang penting dapat difungsikan sebagaimana mestinya. Bahasa (3) yang digunakan menyesuaikan dengan negara yang dituju. Bahasa dasar adalah bahasa Inggris (Moldova, Romania) dan Prancis (Bulgaria). Adapun untuk deskripsi suasana, deskripsi terhadap tokoh, biasanya menggunakan bahasa setempat (negara tempat pertunjukan berlangsung). Untuk lebih komunikatif, dibutuhkan penerjemah langsung, apakah dari bahasa Indonesia ke bahasa lokal (Moskow, Sofia, Kurume, Jepang), ataukah dari bahasa Inggris dan Prancis ke bahasa setempat (NATFIS, Sofia Bulgaria). Sedangkan untuk pengiring (4), yakni penabuh gamelan, yang paling tepat adalah menggunakan penduduk setempat, seperti yang kami lakukan di Moskow, Federasi Rusia (2016). Jika hal tersebut tidak memungkinkan, maka dapat menggunakan rekaman audio, dibantu dengan beberapa tabuhan oleh pendudukan lokal (Bucharest, Moskow). Apa yang telah kami lakukan dapat dilihat https://www.youtube.com/watch?v=110Tpd_MTNM\&t=26s.

\section{PRAKTEK DIPLOMASI BUDAYA DI RUSIA DAN JEPANG}

Dalam melaksanakan diplomasi budaya, kami melakukan berbagai kegiatan internasional, seperti di Bulgaria, Moldova dan Romania di tahun 2015. Tahun 2016 dilanjutkan dengan misi diplomasi budaya di Federasi Rusia dan Jepang. Di Rusia, hal dilakukan berupa memromosikan keberagaman budaya Indonesia, sebuah acara yang diadakan oleh Organisasi Mahasiswa dan Pelajar Indonesia di Moskow, PERMIRA, dengan menyelenggarakan festival seni budaya Indonesia yang di pusatkan di Universitas Persahabatan Rusia (RUDN) di Kota Moskow. Dalam kesempatan tersebut, tidak hanya memainkan wayang tetapi juga diberikan pelajaran berupa menabuh gamelan kepada mahasiswa dan hadirin yang menonton pameran yang diadakan bulan Mei 2016 tersebut. Selama menjalankan tugas diplomasi budaya tersebut, juga 
diberikan pelatihan terhadap warga Rusia dan juga anggota dharma wanita di kedutaan besar RI (KBRI) dengan menabuh gamelan. Hasil latihan ditampilkan sebagai pengiring dalam pentas dalang pada 27 Mei 2016 dengan disaksikan oleh Indonesianis dan para pejabat KBRI. Sajian wayang diplomasi ini mendapat sambutan antusias dari pengunjung mengingat ini adalah kali pertama mereka menyaksikan wayang secara langsung.

Selain di Moskow, perjalanan diplomasi budaya juga dilakukan di Kurume University di Fukuoka Jepang, Juli 2016. Untuk kali ini, bukan wayang yang diajarkan namun mengajarkan kepada penduduk Jepang tentang sejarah dan praktek membatik. Acara tersebut dilakukan tidak hanya di Great Hall of the City yang ditonton oleh ratusan orang tetapi juga dihadapan masyarakat umum, di hadapan para dosen dan mahasiswa. Perjalanan ini kembali berlanjut ke Moscow untuk melanjutkan diplomasi budaya, yakni mengisi dua acara. Pertama adalah berupa Indonesian Expo di Moscow 20-21 Agustus 2016 dan acara ASEAN Day pada tanggal 26 Agustus 2016 di Museum Nasional Darwin di Moskow. Guna memersiapkan gelaran ini, yang kami lakukan adalah mengajari penduduk Moscow menabuh gamelan, menyanyi dan menari. Hasilnya adalah pagelaran yang menarik perhatian penonton. Gaung suara gamelan membahana di Museum Darwin membuat terpana para pengunjung dan pagelaran 6 kali pentas. Di Taman Hermitage selama dua hari ribuan warga Moskow memadati Kawasan tersebut. Rakyat Moskow ternyata sangat antusias menonton wayang diplomasi. Selain wayang itu ditampilkan secara humoristik dan mengambil cerita setempat. Sajian diplomasi budaya dapat dilihat di laman https://www.youtube.com/watch?v=6wgTJGNNkqY\&t=19s).

\section{SIMPULAN DAN SARAN}

Impas dari diplomasi budaya tentu bukan sesuatu hal yang dapat dituai secara cepat apalagi instan namun butuh proses panjang. Setidaknya melalui hal ini, nama Indonesia didengar dan dikenal oleh masyarakat luar serta tercapaian hubungan yang baik antar negara. Penanaman citra baik sangat diperlukan dalam upaya ini, terutama melalui keluhuran budaya dan perilaku. Citra positif sangat membawa peran vital hingga dapat disebut sebagai bagian berpengaruh dalam pengambil keputusan negara dituju. Contoh diplomasi budaya yang membawa hasil positif dapat dilihat dari Cina 
melalui film, dan Jackie Chan menjadi bukti nyata signifikansi aktor non negara dalam memengaruhi opini publik, memenangkan hati dan pikiran masyarakat dunia serta menaikkan citra negara. Film Kungfu produksi Cina mampu melahirkan citra Cina yang modern di mata publik serta menstimuli para diaspora di negeri asing dengan menjadi komunikator di negara ditinggali yang secara tidak langsung turut memromosikan budaya mereka melalui kesetiaan terhadap budaya dan tanah air (Djelantik, 2016). Selain Cina, kita juga dapat berkaca pada kesuksesan Korea Selatan mengenai praktik soft power diplomacy. Melalui drama dan musik, negara ginseng ini sukses menjalankan dipomasi budaya dengan tolak ukur keberhasilan yang sangat nyata. Keberhasilan Korea dapat dilihat dari kemampuannya menggeser keberadaan film maupun musik Hollywood di hati dan benak masyarakat dunia.

Melalui film dan musik, diplomasi budaya secara rutin dilakukan oleh aktor negara kita, departemen luar negeri misalnya, disebut dengan peranan pemulihan ekonomi melalui sektor pariwisata. Dalam upaya ini, departemen luar negeri ikut mendayagunakan potensi kepariwisataan sebagai sumber devisa negara melalui promosi pariwisata budaya dan pendayagunaan serta kerjasama bilateral, regional, antarregional dan global (Wibisono, 2015). Dalam hal ini pelaku non state juga dapat ikut mengambil peran sebagaimana penulis lakukan. Diplomasi budaya dapat membantu memelihara hubungan-hubungan politik maupun non politik yang akan meningkatkan nilai nilai kepentingan bersama.

\section{DAFTAR PUSTAKA}

Djelantik, S. (2016). Diplomasi dalam Politik Global. Bandung: Unpar Press.

Emilia, R. (2013). Praktik Diplomasi. Padang: Baduose Media.

Junior, J. S. N. (2009). Soft Power: The Means To Success In World Politics (revised). New York: PublicAffairs.

Nasution, N. (2012). Dari Aktivis Menjadi Diplomat. Bandung: Mizan.

Purwasito, A. (2011). Pengantar Ilmu Politik. Surakarta: UNS Press.

Purwasito, A. (2015). Komunikasi Multikultural. Yogyakarta: Pustaka Pelajar.

Sosrokartono, R. (1988). Ilmu dan Laku. Surabaya: Citra Jaya Murti.

Wibisono, M. (2015). Tantangan Diplomasi Budaya. Jakarta: LP3ES. 